\title{
DISCÍPULOS DE RAWLS EM BUSCA DE UMA CONCEPÇÃO COSMOPOLITA DE JUSTIÇA DISTRIBUTIVA INTERNACIONAL ${ }^{1}$
}

\author{
Gabriel Cepaluni
}

\author{
Feliciano de Sá Guimarães
}

\begin{abstract}
RESUMO
Neste artigo, argumentamos que alguns "discípulos" de John Rawls, refletindo sobre princípios de justiça internacional, apresentam uma posição mais consistente com o espírito da obra Uma teoria da Justiça do que seu próprio autor. Autores como Charles Beitz e Thomas Pogge defendem mecanismos de justiça distributiva internacional mais condizentes com o cosmopolitismo do "princípio da diferença" da obra Uma teoria da Justiça do que qualquer outro esforço que Rawls faz nesse sentido em sua obra posterior, mais voltada para as questões internacionais: O Direito dos Povos. Mais especificamente, sustentamos que Pogge e Beitz desenvolveram argumentos (a relativização do principio da soberania absoluta dos Estados e a transferência internacional de recursos naturais) mais sólidos para transportar o "princípio da diferença" para o cenário internacional do que a proposta rawlsiana de "dever de assistência", encontrada em O Direito dos Povos. Assim, demonstramos que os discípulos são mais fiéis ao espírito cosmopolita para o plano internacional do que Rawls por conta de três razões: a crença desses autores em uma comunidade global de concidadãos dentro de uma estrutura institucional internacional; a idéia segundo a qual a produção global de recursos coletivos deve ser redistribuida a partir de um princípio distributivo denso; e, por fim, uma redistribuição que somente pode ser justa se exigir reformas morais das instituições internacionais (Fundo Monetário Internacional, Organização Mundial do Comércio, Banco Mundial, principio da soberania etc.) no sentido de melhorar as condições de vida dos individuos mais pobres de todos os povos do sistema. Este artigo pretende, portanto, discutir o legado mais progressista de autores que, ao inspirarem-se em Rawls, desenvolveram argumentos mais condizentes com o espirito cosmopolita para o plano internacional.
\end{abstract}

PALAVRAS-CHAVE: teorias normativas de Relações Internacionais; justiça distributiva; reformas das instituições internacionais.

\section{INTRODUÇÃO}

Neste artigo argumentamos que alguns "discípulos" de John Rawls, refletindo sobre princípios de justiça internacional, apresentam uma posição mais consistente com o espírito da obra Uma teoria da Justiça (1971) do que seu próprio autor. Em nossa visão, Charles Beitz e Thomas Pogge (BEITZ, 1975; 1979; 1999; 2000; 2001; POGGE,

\footnotetext{
1 Uma versão anterior deste artigo foi apresentada no $6^{\circ}$ Encontro da Associação Brasileira de Ciência Política. Agradecemos aos professores Álvaro de Vita (Universidade de São Paulo (USP)) e Nizar Messari (Pontifícia Universidade Católica do Rio de Janeiro (PUC-RJ)) e a dois pareceristas da Revista de Sociologia e Política pelos comentários a versões anteriores deste artigo.
}

1989; 1994a; 1994b; 2001)² defendem mecanismos de justiça distributiva internacional mais condizentes com o cosmopolitismo do "princípio da diferença" da obra Uma teoria da Justiça do que qualquer outro esforço que Rawls faz nesse sentido em O Direito dos Povos (1999).

Sustentamos ainda que Pogge e Beitz desenvolveram argumentos (a relativização do princípio da soberania absoluta dos estados e a transfe-

\footnotetext{
2 Há pelo menos três razões da escolha por Beitz e Pogge. A primeira é que Rawls dialoga prioritariamente com ambos em seus textos acerca da justiça distributiva internacional. A segunda, Beitz é o primeiro autor a transpor a teoria da justiça de Rawls para o cenário internacional. E, por fim, Pogge faz uma crítica e uma conseqüente reformulação da teoria rawlsiana quando aplicada ao plano internacional, sob a supervisão do próprio Rawls.
} 
rência internacional de recursos naturais) mais sólidos para transportar o "princípio da diferença" para o cenário internacional do que a proposta rawlsiana de "dever de assistência", encontrada em O Direito dos Povos.

A razão central dessa diferença encontra-se na defesa que ambos fazem da existência de valores internacionalmente compartilhados (a idéia de uma comunidade global) por indivíduos e povos. Tais valores são contestados por Rawls em $O$ Direito dos Povos, dificultando a criação de eventuais mecanismos de justiça distributiva internacional em consonância com o "princípio da diferença" por ele mesmo criado. Ao não conseguir replicar o espírito cosmopolita desse princípio, Rawls propôs, em $O$ Direito dos Povos, mecanismos distributivos insuficientes para uma proposta de uma reforma cosmopolita do sistema internacional.

No debate sobre justiça internacional, alguns autores arvoram-se mais condizentes com o espírito cosmopolita de Rawls do que ele próprio (BROWN, 1992, p. 175; KUPER, 2000, p. 640; VITA, 2003, p. 96). Tais autores, ao endossarem a mensagem central de Uma teoria da Justiça (publicada originalmente em 1971), acreditam que a concepção de justiça doméstica de Rawls poderia ter uma aplicação mais ampla no sistema internacional. Assim, muitos daqueles que concordam com aspectos centrais da teoria da justiça rawlsiana não escondem certo desconforto com a posição cética de Rawls quanto à possibilidade da criação de princípios internacionais de justiça distributiva.

Uma teoria da Justiça e O Direito dos Povos são obras que apresentam elementos de continuidade. Contudo, Rawls escolheu uma maneira polêmica para "transpor" sua concepção de justiça doméstica para o plano internacional. Isto é, ao imaginar uma sociedade internacional em que os povos não são interdependentes, Rawls desconsiderou que o sistema internacional e suas instituições produzem assimetrias econômicas e sociais, as quais demandam mecanismos de redistribuição de recursos mais profundos e perenes, pois haveria um "compartilhamento moral global" de responsabilidades com relação à criação de desigualdades econômicas internacionais.

Dessa forma, acreditamos que os discípulos são mais fiéis ao espírito cosmopolita para o plano internacional do que Rawls devido a três razões: 1) a crença em uma comunidade global de cocidadãos dentro de uma estrutura institucional internacional; 2) a produção global de recursos coletivos que devem ser redistribuídos a partir de um princípio distributivo denso; 3) uma redistribuição que somente pode ser justa se exigir reformas morais das instituições internacionais (Fundo Monetário Internacional (FMI), Organização Mundial do Comércio (OMC), Banco Mundial, princípio da soberania etc.) no sentido de melhorar as condições de vida dos indivíduos mais pobres de todos os povos do sistema.

Essas razões são mais condizentes com a aplicação de um "princípio da diferença" para o plano internacional do que o mecanismo bilateral e temporário chamado "dever de assistência" exposto em $O$ Direito dos Povos.

$\mathrm{O}$ artigo é dividido em três partes. A primeira compara o "princípio da diferença" do livro Uma teoria da Justiça ao "dever de assistência" da obra O Direito dos Povos para demonstrar que Rawls tornou-se mais conservador com respeito à justiça distributiva neste seu último trabalho. A segunda parte trata do debate acerca da justiça distributiva internacional, enfatizando os pontos em comum entre Pogge e Beitz. Em seguida, discutimos as diferentes visões de Thomas Pogge e Charles Beitz acerca das causas da pobreza mundial. Essa parte tem como objetivo dar sustentação ao nosso principal argumento, de que Pogge e Beitz são mais fiéis ao conceito da justiça distributiva defendido por Rawls em Uma teoria da Justiça (1971) do que o que próprio autor em O Direito dos Povos (1999).

\section{AQUESTÃO DADISTRIBUIÇÃO DE RECUR- SOS PARA RAWLS: DO "PRINCÍPIO DA DI- FERENÇA"AO "DEVER DEASSISTÊNCIA"}

Para Rawls, a estrutura básica da sociedade nacional é o principal objeto da justiça. Em Uma teoria da Justiça, ele define o conceito de estrutura básica como "[...] a forma pelas quais as principais instituições sociais distribuem direitos e deveres fundamentais e determinam a divisão das vantagens obtidas a partir da cooperação social" (RAWLS, 1971, p. 7) ${ }^{3}$. Por sua vez, sociedade é

\footnotetext{
3 Entre as principais instituições sociais estão a constituição política e os principais acordos econômicos e sociais. A proteção legal à liberdade de pensamento e de consciência, mercados competitivos, a propriedade privada dos meios de produção e a família monogâmica são exemplos de instituições (RAWLS, 1971, p. 7).
} 
entendida como "[...] uma associação mais ou menos eficiente de pessoas que em suas relações entre si reconhecem certas regras de conduta e agem na maioria das vezes de acordo com elas" (idem, p. 4).

Conforme o autor, os indivíduos cooperam porque reconhecem que a vida em sociedade oferece mais benefícios do que se vivessem isolados. Contudo, os indivíduos também têm interesses divergentes. Assim, as pessoas não são indiferentes no que se refere a como os benefícios produzidos pela cooperação mútua são distribuídos, porque cada um prefere uma parte maior a uma menor dos benefícios. Um conjunto de princípios é necessário para escolher entre os vários arranjos sociais que determinam a divisão das vantagens e para selar um acordo sobre a distribuição apropriada dos benefícios. Esses são os princípios de justiça social: eles fornecem uma forma de estabelecer direitos e deveres nas instituições básicas da sociedade e definem a distribuição apropriada de benefícios e encargos da cooperação social (ibidem).

Segundo Rawls, os princípios apropriados de justiça das instituições básicas são escolhidos pelos participantes em um esquema cooperativo para a vantagem mútua 4 . $\mathrm{O}$ autor elabora uma "posição original" hipotética em que os indivíduos escolhem esses princípios sob um "véu da ignorância". Eles não conhecem nada sobre suas próprias situações, talentos, profissões ou status sociais. Isto é, não possuem o tipo de conhecimento que poderia prejudicar uma escolha justa de princípios que regeriam a sociedade. Rawls argumenta que os acordos estabelecidos a partir da "posição original" expressam a "justiça como eqüidade", porque "[as partes contratantes] não conhecem as várias alternativas que alterarão seus casos particulares e serão, assim, obrigadas a avaliar os

\footnotetext{
${ }^{4}$ Conforme Rawls, as desigualdades sociais e econômicas são justificadas desde que resultem em maiores benefícios para todos os membros da sociedade, em particular para os menos favorecidos (idem, p. 14-15, et passim). Nesse ponto, Rawls sofreu críticas tanto da direita quanto da esquerda. Nozick (1974) argumenta que se a aquisição inicial da propriedade for justa, o Estado não deve transferir renda. Cohen (1992; 1997), por sua vez, sustenta que os mais ricos podem elaborar uma argumentação convincente para sustentar uma situação em que não se pode transferir renda, pois prejudicaria a situação de todos na medida em que diminuiria os incentivos para os mais talentosos trabalharem mais.
}

princípios apenas com base em considerações gerais" (idem, p. 136-137).

A "justiça como eqüidade" considera os indivíduos como racionais e mutuamente desinteressados; o que não significa dizer que eles sejam egoístas, apenas que possuem certos autointeresses, por exemplo, riqueza, prestígio e desejo de dominação (idem, p. 13). Já a idéia de racionalidade é interpretada nos termos da teoria econômica, no qual os indivíduos selecionam "o meio mais efetivo para um dado fim" (idem, p. 14). Contudo, apenas as partes na posição original, que são pessoas artificiais, são concebidas dessa maneira; os cidadãos de democracias constitucionais são concebidos como pessoas morais livres e iguais.

Essa fórmula para filtrar as "contingências arbitrárias" e obter uma "solução desejada" produz o seguinte princípio de justiça distributiva aplicado à sociedade doméstica: "As desigualdades sociais e econômicas devem satisfazer duas condições. A primeira é que devem estar vinculadas a cargos e posições abertos a todos em condições de igualdade eqüitativa de oportunidades; e a segunda que devem redundar no maior benefício possível para os membros menos privilegiados da sociedade [princípio da diferença]" (RAWLS, 2000, p. 345$)^{5}$.

Em Uma teoria da Justiça, Rawls não acredita que os princípios de justiça possam ser aplicados às relações internacionais. Como eles dizem respeito à estrutura básica da sociedade, que é definida como um sistema fechado e autossuficiente de cooperação mútua, o mundo não poderia ser considerado uma comunidade nos termos de Rawls. Assim, para o autor não há uma sociedade global, pois não há interdependência (cooperação mútua) entre as partes (nações) no âmbito internacional nos mesmos moldes que há entre os indivíduos sob o "véu da ignorância" na "posição original" nacional.

Conforme Rawls: "As condições para o direito dos povos podem requerer diferentes princípios obtidos de formas diferentes. Ficaria satisfeito

\footnotetext{
5 Apesar de estarmos analisando o livro Uma teoria da Justiça, optamos por citar uma formulação mais recente dos seus princípios, assim como aparece na obra O liberalismo político.
} 
se fosse possível formular uma concepção de justiça razoável para a estrutura básica da sociedade concebida provisoriamente como um sistema fechado" (RAWLS, 1971, p. 8).

Conseqüentemente, não existe um excedente a ser distribuído àqueles que estão nas piores posições, pois não há produção internacional de benefícios coletivos (BEITZ, 1979; BROWN, 1992; COCHRAN, 1999). Na seção 58 de Uma teoria da Justiça - "The Justification of Conscientious Refusal" - apenas são discutidos princípios gerais de convivência entre as nações e algumas considerações sobre a guerra justa, nada sendo dito sobre mecanismos de distribuição internacional de recursos.

Em seu último trabalho, Rawls procura ir mais além da discussão da seção 58 de Uma teoria da Justiça no que diz respeito à aplicação de sua teoria às relações internacionais. Em $O$ Direito dos Povos, Rawls considera a existência de uma "posição original internacional". Nessa posição, as partes são representantes de diferentes nações que devem escolher os princípios fundamentais para julgar reivindicações conflitantes entre os diversos povos. Esses representantes também não dispõem de vários tipos de informações, assim como na "posição original" aplicada a sociedades nacionais. Embora saibam que representam diferentes nações, eles não conhecem as circunstâncias particulares de sua própria sociedade, seu poder e força em comparação com outras nações ou sua posição na hierarquia de poder mundial.

Os representantes conhecem o suficiente apenas para possibilitar uma escolha racional que proteja seus interesses, mas insuficiente para permitir que os mais afortunados entre eles possam beneficiar-se de sua condição especial ou que os mais pobres tenham algum privilégio perene. Para Rawls, essa "posição original" estabelece a eqüidade entre as nações. Observa-se que essa igualdade é apenas formal, pois Rawls acredita que os princípios escolhidos não iriam muito além daqueles familiares aos estudantes do Direito Internacional. Por exemplo, os povos devem observar tratados; têm direito à autodefesa, mas nenhum direito de instigar a guerra por outras razões que não a sua própria proteção; e devem promover a ajuda humanitária (RAWLS, 2004, p. 47).

Rawls deixa claro que na falta de uma sociedade global em que indivíduos possam compartilhar valores comuns fica impossibilitada a cons- trução de uma sociedade justa nos moldes do "princípio da diferença", o qual estabelece a reciprocidade entre os cidadãos. A idéia do princípio é de que, para organizar a sociedade nacional em um status igualitário, os indivíduos devem construir mecanismos institucionais perenes, que equilibram as desigualdades geradas aleatoriamente pela distribuição de talentos por meio da distribuição de recursos econômicos e sociais.

As nações são representadas na "posição original internacional" por indivíduos que não sabem nada a respeito das demais nações (suas capacidades e poderes). Esses indivíduos são caracterizados por serem racionais e buscarem a defesa de seus interesses. Esses interesses não significam necessariamente transferir recursos para o quintil inferior da sociedade "global", ou seja, todos os povos que estejam em situação socioeconômica inferior, mesmo que seja para os povos liberais ou decentes ${ }^{6}$. Os interesses colocados por Rawls são vagos, mas poderíamos inferir que estariam mais relacionados com a idéia de autoajuda (sobrevivência) do que interesses reformistas.

Conforme afirmamos, Rawls cria em O Direito dos Povos um mecanismo que busca suprir parte das diferenças socioeconômicas em nível global: o "dever de assistência". Esse princípio significa uma assistência material das sociedades ricas (bem ordenadas e liberais) às sociedades oneradas. O dever de assistência tem alvo específico (determinado país) e é temporário, ao contrário do princípio da diferença para o plano doméstico que não tem alvo e é perene. $\mathrm{O}$ "dever de assistência" serve para incentivar as sociedades oneradas a desenvolverem domesticamente instituições liberais e, assim, serem admitidas na sociedade dos povos bem ordenados, o que em si é visto de maneira positiva. Para o autor, o fim político último da sociedade nacional é tornar-se justa (com instituições liberais). Uma vez esse objetivo

\footnotetext{
6 Os povos decentes fazem parte da sociedade dos povos por conta de dois critérios estabelecidos por Rawls: (a) são povos que não têm objetivos agressivos e que usam a diplomacia para ver seus anseios serem atendidos na sociedade dos povos; (b) ainda que os povos decentes adotem uma doutrina abrangente internamente eles admitem e respeitam com algum grau de liberdade a existência de doutrina diversa entre seus cidadãos, além de parcialmente respeitarem algum grau de direitos humanos (BRAGA, 2008, p.154)
} 
atingido no nível doméstico, o Direito dos Povos não estabelece mais nenhuma meta, como, por exemplo, elevar o padrão de vida dos povos decentes ou dos estados fora-da-Lei.

Rawls sustenta que a sociedade dos povos não terá nenhuma nova razão para diminuir a distância entre a riqueza média dos diferentes povos após ser satisfeito o dever de assistência (princípio de transição) e todos os governos atingirem o liberalismo decente (idem, p. 150, 156). Os povos onerados devem fazer esforços domésticos, mesmo que recebam recursos por meio do "dever de assistência", no sentido de transitarem para a sociedade dos povos liberais. A uma possível "estrutura básica internacional" composta por povos, nada resta a não ser agir de forma emergencial na transferência de recursos.

$\mathrm{O}$ autor sustenta essa posição baseando-se essencialmente na idéia da tolerância. Os povos mais ricos não devem interferir na forma pela qual as estruturas institucionais domésticas dos povos onerados são construídas. Essa interferência não se justificaria segundo a visão mais restrita de direitos humanos (proper human rights) defendida por Rawls. As instituições locais devem ser respeitadas segundo suas diferenças socioeconômicas internacionais ${ }^{7}$. Conforme Beitz, o "dever de assistência" não constrange a distribuição interna dos recursos da sociedade receptora. A concepção interna dessa sociedade será regulada pela concepção nacional de justiça distributiva (BEITZ, 2000, p. 688).

$\mathrm{O}$ autor parece acreditar que apenas uma sociedade global de povos bem ordenados é suficiente para que haja uma verdadeira justiça distributiva internacional. A própria diferença de renda entre sociedades bem ordenadas não é, per se, passível de um eventual princípio da diferença para a esfera

\footnotetext{
7 Rawls tem uma visão thin ou human rights proper dos direitos humanos para a arena internacional. A visão rawlsiana inclui um direito econômico e social básico (direito à subsistência) e não inclui alguns direitos civis e políticos, sobretudo os direitos políticos da Declaração Universal dos Direitos Humanos, que estão associados ao processo democrático. $\mathrm{O}$ "direito à subsistência" está em concordância com o dever de assistência às sociedades oneradas. Isso demonstra que Rawls não está preocupado em estender direitos econômicos, sociais e políticos mais amplos a todos os povos do sistema internacional. Walzer também tem visão parecida sobre a amplitude da moralidade dos direitos humanos no plano internacional (WALZER, 1994, p. 9-10).
}

internacional. Seria como comparar à sociedade doméstica no seguinte sentido: existem cidadãos razoáveis e racionais e cidadãos onerados que precisam de uma assistência dos demais a fim de alcançarem a razoabilidade e a racionalidade. Uma vez isso atingido, a justiça distributiva estaria garantida entre eles e não haveria necessidade de um esforço adicional para redistribuir recursos para o quintil em situação mais desfavorável. A transferência de recursos cessa quando determinado povo adentra a sociedade dos povos bem ordenados. A justificativa para isso gira em torno da injustiça para com as sociedades ricas em arcar, para sempre, com os custos da melhora dos padrões de vida das sociedades oneradas e/ou das sociedades decentes menos ricas. Um princípio de justiça mais forte oneraria injustamente as sociedades que foram responsáveis na conduta de seus assuntos econômicos e políticos em benefícios daqueles povos que não fizeram o mesmo.

Rawls acredita que as causas da pobreza e da injustiça residem no nível doméstico. Quando a sociedade onerada é caracterizada como falida fica claro que a pobreza é resultante da cultura política e econômica nacional. Como o autor não corrobora as idéias de Pogge e de Beitz, segundo as quais existe uma estrutura básica internacional que gera e reproduz desigualdades, não há em $O D i$ reito dos Povos nenhuma referência sobre possíveis condicionantes estruturais que contribuam para a pobreza das sociedades oneradas.

Conforme colocado anteriormente, apenas o "dever de assistência" para os pobres e o mimetismo dos pobres em relação aos ricos fariam que essas sociedades migrassem para o seio da sociedade de povos bem ordenados. Isso demonstra que, pelo menos do ponto de vista do "dever de assistência", há apenas uma condicionante internacional de caráter bilateral (do povo mais rico para os mais pobres ou do grupo de povos mais ricos para os mais pobres) e negativa (cessar o mal). Não há uma condicionante multilateral baseada em um amplo e irrestrito princípio da fraternidade (do sistema institucional global para todos os indivíduos em situação de pobreza em todos os povos) e positiva (diminuir constantemente os níveis de desigualdade global). A idéia rawlsiana sugere que não há entre os povos afinidade suficiente para existir um apoio decisivo ao dever de assistência, sendo ainda mais difícil a aplicação do "princípio da diferença" no âmbito internacional. 
Em O Direito dos Povos, Rawls argumenta que a visão cosmopolita tradicional de Beitz não está apenas preocupada com a justiça e a estabilidade pelas razões certas da sociedade nacional. Pelo contrário, Beitz preocupa-se com o bem-estar da pessoa e com a possibilidade de suas condições serem melhoradas em quaisquer circunstâncias, e não apenas por meio da justiça entre as sociedades. Beitz prega a necessidade de mais distribuição global, mesmo depois de cada sociedade ter alcançado instituições internamente justas, contrariando o mero "dever de assistência". O que importa para ele é o bem-estar do indivíduo representativo - aquele que ocupa o quintil inferior de renda e riqueza - que se encontra na posição mais desfavorável globalmente, ao passo que o Direito dos Povos toma como importante a justiça e a estabilidade de sociedades liberais e decentes (RAWLS, 2004, p. 157).

Em O Direito dos Povos, Rawls afasta-se da idéia de que o indivíduo deve ser beneficiário dos mecanismos distributivos globais baseados no princípio da fraternidade, e pensa a justiça distributiva internacional a partir de princípios menos precisos, tais como povos, sociedades oneradas e liberais. Já em Uma Teoria da Justiça, a distribuição de recursos e posições de prestígio social está intimamente ligada a um conceito mais bem acabado e claro: os indivíduos - independentemente de seus locais de nascimento.

O "princípio da diferença" desenvolvido em Uma teoria da Justiça é mais próximo do sentido moral da "justiça como imparcialidade" defendido por Brian Barry $(1995 ; 1998)$ do que o "dever de assistência" de O Direito dos Povos. O "dever de assistência" dificilmente transferirá recursos em larga escala para os cidadãos mais pobres do planeta. Pelo contrário, cidadãos pobres de sociedade decentes ou os cidadãos pobres dos estados Fora-da-Lei ficarão de fora da transferência. Para ser efetivo, o "princípio da diferença" exige fortes reformas institucionais no plano doméstico, assim, transportá-lo para o plano internacional exigiria densas reformas morais nas instituições internacionais que geram desigualdades (OMC, FMI, Banco Mundial etc.). Contrariamente, o sentido moral do "dever de assistência" - na medida em que Rawls não acredita na existência de uma estrutura global básica que engendra desigualdades profundas, mas apenas em uma vaga "posição original" composta por representantes de po- vos - não exige qualquer reforma nas instituições internacionais. No máximo, exige o aprimoramento dos mecanismos bilaterais de transferência de recursos nos moldes da United States Agency for International Development (Usaid) e European Commission's Humanitarian Aid Office (ECHO).

A questão das reformas das instituições internacionais está ligada a uma discussão sobre as causas da pobreza. Conforme afirmamos, enquanto os cosmopolitas acreditam em um sistema internacional que gera desigualdades, Rawls e os comunitaristas, como Walzer, preferem pensar as causas da pobreza como essencialmente domésticas. Vejamos detalhadamente a discussão.

\section{O DEBATE SOBRE A JUSTIÇA DISTRIBU- TIVAINTERNACIONAL}

O debate sobre a justiça distributiva internacional está relacionado à escolha entre diferentes causas da pobreza e qual o tipo de justificação moral que se apresentará para resolvê-las. Beitz e Pogge estão interessados em pensar como a distribuição de recursos pode ser resolvida a partir de causas majoritariamente estruturais. Para esses autores, existe um sistema internacional com determinadas instituições que prorrogam as atuais desigualdades socioeconômicas entre os indivíduos. Ambos pretendem criar propostas moraisreformistas para o sistema internacional. Já autores como Rawls, Walzer e Sandel (WALZER, 1983; 1990; 1994; 2006; SANDEL, 1982; 1984) não estão preocupados com fatores de ordem sistêmica, mas sim com as condicionantes de ordem doméstica para explicar as causas fundamentais da pobreza. Em outras palavras, a pobreza seria mais uma conseqüência dos problemas oriundos da cultura política e econômica doméstica do que resultado de pressões negativas do exterior.

Pogge e Beitz acreditam que a desigualdade de recursos entre países e, sobretudo, indivíduos continua a alastrar-se pelo mundo exatamente por causa dos efeitos perversos das instituições políticas e econômicas globais - o princípio tradicional de soberania absoluta e instituições como FMI, OMC, etc. Pogge e Beitz acreditam na existência de uma "estrutura básica global" que é por definição injusta e que favorece a continuidade da desigualdade. A combinação de níveis extremos de pobreza absoluta com níveis também muito elevados de riqueza causa indignação exatamente porque se os níveis de desigualdade são muito grandes, sacrifícios 
muito pequenos de renda, riqueza e bem-estar dos mais abastados (os $20 \%$ mais ricos do planeta) seriam suficientes para abolir pelo menos a pobreza extrema do mundo. De modo geral, Beitz e Pogge defendem não apenas uma reforma política dessa estrutura, mas uma reforma moral que obrigue os mais favorecidos - os governos dos países mais ricos - a contribuírem para a melhora das condições de vida do quintil inferior dessa estrutura. Com base nessa visão estrutural, ambos advogam princípios de justiça distributiva com alcance global. A comunidade alvo a ser reformada não seria apenas nacional, mas também a internacional.

Milner lembra que somente os cosmopolitas, principalmente Beitz e Pogge, têm algo a dizer sobre os efeitos nem sempre benignos das instituições internacionais, elemento central da estrutura básica global. Como os cosmopolitas analisam as questões sobre o alcance das obrigações morais dos ricos e, sobretudo, visam reformar as instituições internacionais para beneficiar os mais pobres; a autora sustenta que, ao renunciar um pouco de seus ganhos, os países ricos poderiam construir ou reformar organizações internacionais beneficiando os países pobres. Para Milner, as instituições internacionais vigentes falharam em pelo menos quatro pontos no que diz respeito às expectativas de participação institucional dos países mais pobres, contrariando as perspectivas teóricas de institucionalistas como Keohane (1984) para o qual a mera existência de instituições seria salutar aos desprivilegiados, os quais veriam dirimidas as diferenças de poder uma vez lá dentro. Esse "fracasso" das instituições devese a: 1) elas não conseguiram controlar o comportamento dos mais ricos; 2) não conseguiram prover as informações sobre as preferências dos atores de maneira simétrica para que se pudessem prever os comportamentos com mais precisão; 3) a reciprocidade não ajudou as economias menos diversificadas e que têm menos a oferecer em troca de algo; 4) as instituições internacionais não têm conseguido alterar as políticas domésticas dos países pobres de maneira a solucionar problemas crônicos (as recomendações do FMI seriam o exemplo mais contundente) (MILNER, 2005, p. 36, 45-48).

Dentro de uma perspectiva normativa distinta, Walzer alega que necessidades locais dos indivíduos sempre têm preferência em relação às necessidades de ordem sistêmica, exatamente porque aquilo que os cidadãos precisam para prover soluções somente tem sentido se interpretado à luz da cultura nacional. Nossos compatriotas teriam preferência com relação à distribuição de recursos, havendo uma distinção clara entre "nós" e "eles". A justiça distributiva internacional é ilusória porque assume que todos compartilham princípios e valores, o que seria impensável na visão de Walzer, segundo o qual a mais ampla esfera de justiça é a comunidade política nacional. Walzer enxerga o problema da justiça como decorrente de questões nacionais (domésticas) e relacionados ao Estado. Daí sua pregação no sentido de fazer-se justiça, não por meio de reformas em uma eventual estrutura global ou pelo enfraquecimento da soberania, como querem Beitz e Pogge, mas sim pelo fortalecimento do State-making (WALZER, 2006, p. 135-136). Walzer estaria embasado naquilo que Pogge chama de "nacionalismo explanatório", que impossibilita qualquer fundamento moral para um princípio de justiça distributiva internacional (POGGE, 2005, p. 6-7).

Rawls comunga, em certa medida, com o "nacionalismo explanatório" de Walzer. Em O Direito dos Povos, o autor utiliza a polêmica obra de David Landes - The Wealth and Poverty of Nations para justificar que a causa da pobreza reside na cultura e política local. Landes explica o subdesenvolvimento a partir da cultura nacional de forma anedótica e controversa. Há até mesmo uma tentativa de associar o clima ao desenvolvimento econômico, passando por sua influência nos traços culturais locais (LANDES, 1999). Ao utilizar Landes como base de sua justificação, Rawls rejeita definitivamente qualquer discussão sobre a existência de uma estrutura internacional injusta e seus possíveis efeitos sobre a vida dos indivíduos, argumentando que "as virtudes políticas e cívicas dos membros nacionais" (RAWLS, 2004, p. 153) definem os níveis de justiça e, conseqüentemente, o desenvolvimento socioeconômico.

Para Rawls, os povos não têm desejos idênticos de aumento de renda e riqueza a fim de alcançar doutrinas específicas do bem. Os interesses dos povos são, no máximo, manter a integridade territorial e a segurança de seus cidadãos, mantendo instituições justas e livres, dentro dos parâmetros culturais locais. Mais uma vez, as sociedades econômicas e sociais injustas devem receber recursos temporários das nações liberais por meio de mecanismos bilaterais. Não cabe às nações ricas qualquer esforço sustentável para alterar os padrões locais de justiça, não permitindo 
qualquer intervenção de caráter humanitário de cunho socioeconômico ou instrumentos de transferência mais densos.

Como Rawls, em O Direito dos Povos, não se preocupa com a eventual existência de cidadãos globais que se vêem como iguais e livres - para ele os indivíduos vêem-se de acordo com suas imagens nacionais -, não seria legítimo construir instituições internacionais com princípios fundados na defesa do indivíduo em qualquer circunstância ou lugar (WENAR, 2006, p. 103).

Beitz e Pogge discordam plenamente dessa visão rawlsiana. Essa discordância é normalmente seguida de análises que propiciam um conjunto de justificação moral a fim de avaliar as responsabilidades e deveres em torno de potenciais princípios de justiça distributiva no plano internacional, tendo como base a defesa dos indivíduos em seu sentido mais amplo. Além disso, ambos preferem olhar para um tipo de comunidade moral mais condizente com o espírito cosmopolita. Veremos essas análises na próxima seção.

\section{CHARLES BEITZ E THOMAS POGGE: MAIS PRÓXIMOS DE UM "PRINCÍPIO DE DIFE- RENÇA"RAWLSIANO PARAAARENAGLO- BAL}

\section{IV.1. Charles Beitz e a transferência internacio- nal de recursos naturais}

Como pudemos observar, Rawls é cético em Uma teoria da Justiça quanto à possibilidade de aplicação de seus princípios de justiça ao âmbito internacional. Contudo, em meados da década de 1970, em artigo intitulado "Justice and International Relations" 8 , Charles Beitz via a possibilidade de aplicar-se a teoria de Rawls às relações internacionais, principalmente o seu princípio de justiça distributiva. Aceitando os dois princípios básicos de justiça de Rawls, Beitz concluiu que o autor negligenciou importantes aspectos de sua teoria quando aplicada ao plano global.

Beitz argumenta que há duas razões para promover-se a justiça distributiva internacional. O primeiro argumento concebe os estados como entidades autossuficientes, nas quais posses diferenciadas de recursos naturais são geradoras de de-

\footnotetext{
8 Posteriormente, esse artigo foi reimpresso com pequenas alterações na terceira parte do livro de Charles R. Beitz (1979).
}

sigualdades que precisam ser reduzidas. O segundo argumento sustenta que os estados vivem em um sistema internacional interdependente no qual suas interações geram desigualdades entre os indivíduos.

Considerando os estados nacionais como entidades autossuficientes, Beitz utiliza o argumento da "posição original" de Rawls para pensar no desenvolvimento de princípios de justiça internacional.

Ele concorda com os dois princípios de justiça de Uma teoria da Justiça, mas acredita que o autor negligencia a questão dos recursos naturais. Como os participantes de uma "posição original" doméstica não deveriam levar em consideração os talentos naturais nas escolhas de suas futuras posições sociais por causa da "arbitrariedade moral" na obtenção dessa vantagem, os recursos naturais disponíveis em cada um dos estados deveriam ser vistos de forma semelhante no plano internacional. Isto é, como a disposição dos recursos naturais no planeta é arbitrária, seria necessário pensar como distribuir de uma maneira mais eqüânime a riqueza oriunda dessa diferença (BEITZ, 1975, p. 367).

Conforme Beitz, o "véu da ignorância" na "posição original" deveria obrigar as partes a examinar a distribuição desses recursos. Assim, ele argumenta que a distribuição natural de recursos é um caso mais puro de arbitrariedade moral do que a distribuição de talentos, porque, "como os talentos, a titularidade dos recursos é arbitrária no sentido em que eles não são merecidos. Mas, diferentemente dos talentos, os recursos não são normalmente atrelados às pessoas. [...] Embora sentimos que a possessão dos talentos confere o direito de controle e de usufruto do benefício pelo seu uso, temos uma sensação diferente com relação aos recursos" (idem, p. 368-369).

Beitz também sustenta que é errado assumir que onde não há cooperação social não há problemas de distribuição de recursos. Rawls argumenta que no plano internacional não há cooperação social suficiente para que haja problemas nesse sentido. Para Beitz, os laços morais não são limitados àqueles com quem nós nos envolvemos exclusivamente em esquemas cooperativos. Os participantes da "posição original" internacional não deveriam escolher suas posições sociais sabendo de antemão quais recursos viriam a possuir. Portanto, possivelmente concordariam com o princí- 
pio da redistribuição de recursos se fizessem suas escolhas sob o "véu da ignorância" (idem, p. 369370). Conforme Beitz, o argumento a favor da redistribuição internacional de recursos coadunase com o pressuposto de sociedades autossuficientes. Contudo, empiricamente, o argumento em defesa da existência de um sistema de interdependência econômica internacional parece ser mais convincente: "Tudo o que disse até agora é consistente com o pressuposto de que as nações são esquemas cooperativos autossuficientes. Entretanto, há fortes razões empíricas para pensar que esse pressuposto não seja mais válido" (idem, p. 373).

$\mathrm{O}$ segundo argumento de Beitz faz que o primeiro pareça menos importante, pois torna a necessidade de redistribuição internacional ainda mais premente. A interdependência econômica internacional "envolve um padrão de relacionamento que é amplamente involuntário do ponto de vista dos participantes desprivilegiados, produzindo benefícios para alguns enquanto impõe perdas a outros" (idem, p. 374) $)^{9}$. Assim, não podemos limitar o conceito de Rawls de sociedade ao âmbito do Estado Nacional, porque a rede de relações internacionais interdependentes cria um "esquema global de cooperação social” (idem, p. 376).

Esse esquema global de cooperação social entre os estados gera benefícios coletivos que devem ser redistribuídos. Nesse ponto, há uma diferença importante entre os dois autores. Enquanto Beitz acredita na existência de um sistema internacional com recursos coletivos suficientes para serem distribuídos, Rawls nega essa possibilidade, pois em um mundo de unidades autossuficientes não há produção coletiva de bens

9 Em Liberalismo e justiça distributiva, Beitz faz um paralelo entre o debate dos realistas versus liberais ("interdependentistas") com a discussão sobre justiça distributiva internacional (BEITZ, 1999, p. 27-28). De fato, a discussão a respeito da interdependência econômica e de suas implicações não é nova na disciplina de Relações Internacionais (WALTZ, 1970; KEOHANE \& NYE (1989) [1977]; ANGELL, 2002 [1933]). Nesse sentido, também não nos concentraremos nas influências e nas relações que existem entre os chamados três grandes paradigmas das Relações Internacionais (realismo, institucionalismo e construtivismo) e o debate sobre justiça distributiva internacional, pois esse tema foi amplamente discutido em artigo recente publicado em Contexto Internacional (GUIMARÃES, 2008). para serem divididos de maneira mais equânime. $\mathrm{Na}$ visão rawlsiana, os recursos são majoritariamente nacionais, gerados pelas instituições políticas domésticas e, somente a partir delas, esses recursos devem ser distribuídos.

Beitz assegura que a imagem Estado-cêntrica do sistema internacional perdeu relevância por causa da ascensão da interdependência econômica. Assim, princípios de justiça distributiva "devem ser aplicados em primeira instância para o mundo como um todo; em seguida, aos estados nacionais". Conforme o autor, o princípio global mais apropriado seria algo parecido com "a concepção geral de justiça de Rawls" (idem, p. 383). $\mathrm{O}$ autor argumenta que se considerarmos o mundo totalmente interdependente é possível enquadrálo no esquema de cooperação rawlsiano para o plano doméstico e, conseqüentemente, aplicar o princípio da diferença para todos os indivíduos no âmbito global (BEITZ, 1979, p. 132).

Em artigo recente, Beitz (2000, p. 671) mantém a posição segundo a qual há possibilidade de pensar-se uma sociedade global interdependente e, a partir dela, pensar em mecanismos mais densos de distribuição de recursos. Conforme argumentamos, Rawls é menos incisivo no tema distributivo em sua última obra porque está preocupado com o problema da intolerância. Forçar a mudança das instituições domésticas de outros países a partir de um centro justo e desenvolvido, tendo como base a defesa dos interesses dos indivíduos menos favorecidos de países pobres, poderia ser lido como uma imposição. Entretanto, para Beitz, da mesma forma em que há diversas e incompatíveis doutrinas do bem coexistindo no plano doméstico, também há no plano externo a mesma situação (ibidem). Conseqüentemente, os parâmetros de análise rawlsiano aplicáveis em Uma teoria da Justiça continuam a ser aplicáveis em possíveis reformas globais.

Beitz prega uma interpretação alternativa ao liberalismo social de Rawls: o liberalismo cosmopolita. Embora seja consistente com uma concepção do mundo como uma sociedade internacional composta por sociedades domésticas, a visão cosmopolita não denota privilégio moral às sociedades domésticas. O liberalismo cosmopolita vê o mundo social composto por pessoas - não por sociedades ou povos como categorias abstratas e insiste que os princípios de justiça tenham como alvo principal os interesses fundamentais dos in- 
divíduos (idem, p. 677). Para o autor, a tentativa de Rawls de justificar a justiça distributiva internacional em termos dos interesses dos povos, no lugar das pessoas, abre espaço para problemas éticos em relação aos direitos humanos (ver nota 7). Beitz acredita, também, que o "dever de assistência" impõe exigências distributivas importantes à sociedade global, embora com menos ênfase do que uma teoria cosmopolita exigiria.

\section{IV.2. Thomas W. Pogge e a relativização do prin- cípio de soberania absoluta}

Thomas W. Pogge está interessado em ampliar para as relações internacionais a idéia de "consenso sobreposto" de Rawls. Em O liberalismo político Rawls procura entender como interesses comuns, um modus vivendi, não são suficientes para garantir relações estáveis e justas em sociedades democráticas liberais ao redor do mundo, acreditando que o "consenso sobreposto", um acordo sobre certos valores compartilhados, seria uma garantia mais substancial nesse sentido (RAWLS, 2000, p. 179-219). Conforme Pogge, o modus vivendi é um acordo que se funda no equilíbrio de poder entre as nações. É uma solução melhor que a destruição mútua das partes em conflito, mas está longe de ser um acordo fundado em considerações morais.

O problema central da ordem contemporânea não seria a ausência de um governo mundial. A ordem global é moldada por acordos intergovernamentais e instituições internacionais - "que são baseadas em deliberações providenciais constituídas pela atual distribuição de poder" (POGGE, 1989, p. 218). Nesse ambiente internacional, "estadistas e cidadãos não têm uma razão moral para desejarem que seus estados apoiem a atual ordem [internacional], a qual é vista meramente como a cristalização de um equilíbrio de poder momentâneo" (ibidem; grifos no original).

Pogge procura demonstrar que a ordem internacional atual é um modus vivendi, e que as instituições internacionais são mal-sucedidas porque não possuem valores morais compartilhados (idem, p. 222). Os governos no atual modus vivendi participam de um esquema que incentiva comportamentos competitivos, procurando moldar as instituições internacionais conforme seus autointeresses e contrariamente aos de seus adversários (ibidem). Conclui-se que as relações internacionais nesse modus vivendi não são nem pacíficas nem justas, pois os termos do modus vivendi refletem essencialmente o equilíbrio de poder internacional que está amplamente descolado de qualquer consideração moral (idem, p. 221).

Conforme Pogge, devemos "transcender o modus vivendi prevalecente" e caminhar na direção de uma ordem social baseada em valores morais compartilhados (idem, p. 227). Deveríamos substituir instituições que incentivam a barganha, permeadas pela noção de equilíbrio de poder, por regimes internacionais que enfatizem princípios de justiça comuns. Um valor compartilhado não é apenas interesse comum ou a simples coexistência. Um esquema institucional baseia-se em valores compartilhados pelos seus participantes e são incorporados por instituições que regulam o comportamento estatal (idem, p. 228). Seria, portanto, um pré-requisito para a ordem internacional baseada em valores que as "sociedades aceitassem - moralmente em vez de apenas providencialmente - a existência continuada umas das outras, assim como os valores centrais dos seus contratos sociais domésticos" (ibidem). Pogge lista três outras condições necessárias para um "esquema institucional baseado em valores": 1) as partes convencer-se-iam de que deveria existir um esquema justo para a distribuição dos benefícios e dos encargos entre elas, não levando em conta seus interesses ou alterações de poder entre os membros; 2) as partes poderiam identificar e talvez ampliar os valores comuns; 3 ) cada parte estaria disposta a repensar seus valores em alguma medida (idem, p. 229).

Pogge estabelece uma última e decisiva condição para a transformação da ordem internacional vigente: o "pluralismo internacional", ou seja, a idéia de que pessoas inteligentes, cultas e com boa vontade apoiarão diferentes formas "razoáveis" de organizações sociais (idem, p. 230).

Existem duas razões que explicam por que devemos aceitar a idéia de "pluralismo internacional": o realismo e a plausibilidade. O realismo levanos à conclusão de que podemos superar a fragilidade de um modus vivendi, porque a aceitação do compartilhamento moral do "pluralismo internacional" asseguraria a existência mútua, reduzindo o perigo de uma guerra global entre sociedades poderosas com interesses aparentemente divergentes. Em segundo lugar, Pogge argumenta que a condição do "pluralismo internacional" é plausível. Ele argumenta que não podemos estabelecer valores ou fins verdadeiros sobre as quais 
a sociedade deveria ser organizada, nem podemos defender razoavelmente uma única organização social justa.

$\mathrm{Na}$ maioria das vezes, devemos procurar encarar nossos desacordos sobre essas questões como "desacordos razoáveis". Assim, podemos trabalhar conjuntamente na direção de um mundo em que diferentes posições razoáveis podem coexistir em um ambiente internacional pacífico e amigável (idem, p. 230-232).

Pogge inicia sua teoria tentando buscar um ideal de justiça para sociedades fechadas. Rawls refletiu sobre a aplicação da justiça distributiva para sociedades fechadas, mas Pogge considerou que esse argumento só é válido como um exercício teórico, uma vez que de fato existe um sistema internacional interdependente.

Conforme Pogge (idem, p. 251), o princípio de redistribuição global de recursos de Beitz foi influenciado pela interpretação equivocada de Nozick de como Rawls trata as possessões naturais. Para Rawls, os indivíduos têm direito às suas possessões naturais, assim como a tirar o melhor proveito possível delas. Rawls propõe que os efeitos distributivos de instituições sociais, enviesados em favor daqueles que possuem determinados tipos de talentos, sejam retificados (VITA, 2006, p. 94). No mesmo sentido, diferenças discrepantes de renda devem ser reduzidas para que indivíduos igualmente talentosos possam competir em condições relativamente igualitárias.

Antes do lançamento de O Direito dos Povos, Pogge defendeu a idéia segundo a qual a interdependência global é compatível com a teoria de Rawls, porque ela está afinada com a idéia moral de uma estrutura básica que amenize as injustiças sociais por meio do princípio da diferença. Assim, Pogge acreditava que "a globalização [da concepção de justiça rawlsiana] não é incompatível com os elementos essenciais do trabalho de Rawls" (POGGE, 1989, p. 240).

Mesmo após 1999, com o lançamento de $O$ Direito dos Povos, Pogge continuou a defender a idéia de transposição do "princípio da diferença" para o plano internacional. Em trabalho mais recente, o autor elaborou três argumentos que justificam uma clara conexão (interdependência) entre os países ricos e os pobres: 1) as posições sociais iniciais de ambos emergiram de um único processo histórico que foi permeado por uma sé- rie de injustiças. Entre elas, podemos citar: genocídios, colonialismos e escravidões; 2) os ricos e os pobres dependem de uma base comum de recursos naturais, da qual os pobres são em grande parte excluídos; 3) os dois grupos de países coexistem em uma única ordem econômica global que tem uma forte tendência a perpetuar e até mesmo agravar as desigualdades econômicas globais (POGGE, 2001, p. 14).

A obra de Pogge não visa apenas demonstrar o argumento de que as injustiças internacionais devem ser combatidas, mas tem também uma proposta de reforma institucional: a do Dividendo Global de Recursos (DGR). Conforme ela, todos os estados que utilizam os recursos escassos em seus territórios seriam taxados de modo a beneficiar as pessoas menos privilegiadas do mundo (POGGE, 1994a). Uma das principais propostas de Pogge para amenizar as desigualdades socioeconômicas em nível global é a criação de uma "taxa global sobre recursos" nos mesmos moldes rawlsianos para o plano doméstico. Para Rawls, a cobrança de impostos deve estar voltada para o benefício máximo dos menos privilegiados. Pogge propõe lógica semelhante para a arena global, porém com uma taxação variável sobre a extração dos recursos naturais (petróleo, minerais, recursos renováveis etc.). As taxas seriam pagas não pelos indivíduos compradores dos recursos, mas por aqueles que os extraem. Isso mitigaria um possível viés contra os países ricos que a taxa acarretaria - por ser grande importador de petróleo, o Japão não pagaria a taxa. O pagamento seria uma questão de direito (entitlement) e não de caridade. A aceitação à taxa seria voluntária. Segundo o autor, uma sociedade justa aceitaria a taxação desde que assim o fizesse democraticamente (idem, p. 199-202).

Os governos nacionais seriam responsáveis pela arrecadação e, também, pela transferência dos valores. Isso não exigiria uma burocracia centralizada (governo mundial) responsável pela arrecadação, controle e repasse dos recursos. Os governos nacionais transfeririam o que foi arrecadado para os governos dos países mais necessitados e seriam supervisionados pela Organização das Nações Unidas (ONU) Por outro lado, alguns governos são corruptos o suficiente para desviarem os recursos. Nesses casos, Pogge sustenta que a administração direta das transferências deveria ser feita pelas agências da ONU (World Food Program, 
Fundo das Nações Unidas para a Infância (Unicef), Organização Mundial de Saúde (OMS) etc.) e por organizações não-governamentais idôneas (Oxfam). Esses organismos, entretanto, precisam ser reformados a partir de princípios morais mais voltados aos interesses dos menos favorecidos (idem, p. 202).

Para Pogge, a existência de um esquema institucional global mostra que os estados não são unidades autossuficientes - como defende Rawls - que podem autonomamente implementar políticas a partir de seus próprios princípios de justiça. Eles são claramente afetados por fatores internacionais. Para o autor, há dois aspectos sistêmicos que têm peso decisivo no plano doméstico dos países pobres: o international resource privilege e o international borrowing privilege. No atual sistema, qualquer grupo que controlar os meios de coerção em um país é internacionalmente reconhecido como legítimo. Esse governo possui o direito de vender seus recursos e pedir emprestado dinheiro para qualquer finalidade. Isso significa que tais direitos eventualmente se revertem para os poucos indivíduos no poder, e em detrimento da maioria. $\mathrm{O}$ autor deixa claro que esses aspectos da ordem internacional são impostos pelas nações mais ricas e acalentados pelas elites corruptas dos países pobres, contribuindo significativamente para a perpetuação da pobreza. Assim, as conexões institucionais de nível internacional tornam obsoleta a idéia de que os países podem discordar pacificamente sobre o conteúdo da justiça internacional na seara da distribuição de recursos. Se todos são afetados pelas pressões internacionais, todos devem aspirar uma base moral única para julgamentos da ordem global. O argumento de que os países ricos não são responsáveis pelos problemas domésticos dos países pobres é impensável (POGGE, 2002, p. 33, 133).

A idéia de uma taxa global somente tem sentido se Pogge partir do pressuposto de que há produção de benefícios coletivos dentro de uma estrutura institucional internacional. Esses benefícios coletivos produzidos de maneira desigual devem ser redistribuídos com base em um princípio fundamental de justiça da estrutura institucional internacional. Para que isso ocorra, tais atores devem ser reformados (instituições, estados e indivíduos), tendo como parâmetro a discussão moral em torno da justiça como imparcialidade. A taxação de Pogge seria a proposta mais concreta de um "princípio da diferença" rawlsiano para o plano global, ainda que sua operação e ambiguidades sejam óbvias.

\section{VI.3. O Direito dos Povos e a abdicação do indi- vidualismo ético}

Conforme afirmamos anteriormente, em Uma Teoria da Justiça Rawls demonstrou não acreditar na possibilidade da aplicação de seus princípios de justiça ao plano internacional sem consideráveis modificações. As restrições de Rawls sobre a possibilidade de aplicação de sua teoria às relações internacionais ficam claras também em O liberalismo político - livro em que o autor revisa alguns aspectos de Uma teoria da Justiça, mas no qual mantém o espírito de sua obra anterior: "[...] suponho que a estrutura básica da sociedade seja a de uma sociedade fechada, isto é, devemos considerá-la autossuficiente e sem relações com outras sociedades. Seus membros só entram nela pelo nascimento e só a deixam pela morte. Isso nos permite falar deles como membros nascidos em uma sociedade onde passarão a vida inteira. Que uma sociedade seja fechada é uma abstração considerável, que se justifica apenas porque nos possibilita concentrarmo-nos em certas questões importantes, livres de detalhes que possam nos distrair" (RAWLS, 2000 [1993], p. 54).

Como vimos, em $O$ Direito dos Povos, Rawls procura estender a concepção de justiça internacional exposta em Uma teoria da Justiça para além do direito internacional, manifestando-se contrário a qualquer princípio de justiça distributiva internacional.

Do ponto de vista moral e apesar das dificuldades práticas, preferimos a argumentação de Charles R. Beitz e Thomas W. Pogge à de Rawls. Ambos são fortemente favoráveis a princípios redistributivos internacionais. A aceitação desses princípios depende da crença de que vivemos em uma sociedade internacional interdependente, que traria embutida um mecanismo de perpetuação e de aprofundamento de desigualdades econômicas que necessitam ser retificadas.

As propostas de Beitz e Pogge, ainda que insipientes e controversas, buscam estender ao plano internacional um conjunto de instituições morais voltadas aos interesses dos indivíduos mais pobres. No entanto, a construção de uma proposta mais sustentada de "princípio de diferença" para o sistema internacional requer mais discussões e 
diferentes perspectivas. Talvez a pergunta mais difícil de ser respondida seja como construir um arcabouço institucional internacional que transfira recursos sem violar as culturas locais, mesmo em regiões muito pobres. Com efeito, o maior problema de $O$ Direito dos Povos não é tanto a negação da estrutura internacional injusta, mas a abdicação do individualismo ético, base moral de Uma Ttoria da Justiça, em nome de um nacionalismo ético pouco preciso (a própria idéia de povos representados na posição original internacional).

O que nos parece claro, contudo, é que Pogge e Beitz procuram suprimir essa lacuna. Ao defenderem a existência de uma comunidade global de valores que gera bens coletivos ainda que injusta e passível de reformas, ambos abrem espaço para discussão dos caminhos a serem trilhados no sentido de uma ordem global mais justa pelos povos vistos em seu conjunto (estados e indivíduos).

\section{CONCLUSÕES}

O principal objetivo deste artigo foi examinar o debate em torno da possibilidade de uma concepção de justiça rawlsiana para o plano internacional. Nesse sentido, fizemos uma análise sobre a abordagem da justiça internacional apresentada por Rawls em Uma teoria da Justiça. Posteriormente, buscamos localizar as propostas de Charles Beitz e de Thomas W. Pogge no debate acerca da justiça distributiva internacional. Finalmente, ex- pusemos a reflexão dos dois discípulos de Rawls, que discordam do ceticismo do autor quanto à transposição de sua teoria para o plano global.

Concluímos que as obras dos dois autores são mais condizentes com o espírito cosmopolita do que o próprio Rawls em $O$ Direito dos Povos, porque acreditam em um mundo interdependente cuja estrutura institucional internacional tem gerado desigualdades constantes em prejuízo dos mais pobres. Além disso, a defesa de transferência internacional de recursos naturais de Beitz, a relativização do princípio de soberania e a proposta de taxação global de Pogge, ainda que pouco factíveis, são mais condizentes com percepções morais de cunho cosmopolita, exatamente por terem foco no indivíduo em qualquer circunstância e lugar, e não em uma idéia de povos abstratamente construída.

É difícil não aceitar as idéias de Rawls para o plano internacional se adotarmos o ponto de vista dos habitantes dos países pobres, onde a desigualdade e sua visualização são bem maiores do que nas sociedades bem-ordenadas. Certamente, muitos dos problemas gerados em tais países têm origens domésticas. Contudo, acreditamos que a interferência de nações mais poderosas nos assuntos domésticos das nações desafortunadas e também uma ordem internacional que favorece aos mais ricos colaboram para a manutenção e a ampliação das desigualdades globais. Mas isso ainda é uma agenda aberta a novas pesquisas e debates.

Gabriel Cepaluni (gabi.cepal@gmail.com ) é Doutor em Ciência Política pela Universidade de São Paulo (USP) e professor da Universidade Estadual Paulista (Unesp), campus de Franca.

Feliciano Guimarães (Feliciano.Guimaraes@fgv.br) é Doutor em Ciência Política pela Universidade de São Paulo (USP) e Professor da Fundação Getúlio Vargas (FGV).

\section{REFERÊNCIAS BIBLIOGRÁFICAS}

ANGELL, N. 2002 [1933.] A grande ilusão. Brasília: UNB.

BARRY, B. 1995. Justice as Impartiality. Oxford: Oxford University.

1998. International Society from a Cosmopolitan Perspective. In: MAPEL, D. \& NARDIN, T. (eds.). International Society. Princeton: Princeton University.
BEITZ, C. R. 1975. Justice and International Relations. Philosophy and Public Affairs, Princeton, v. 4, n. 4, p. 360-389, Summer. Disponível em: http://www.jstor.org/stable/ 2265079. Acesso em: 23.ago.2010.

1979. Political Theory and International Relations. Princeton: Princeton University. . 1999. Liberalismo internacional e justiça 
distributiva. Lua Nova, São Paulo, n. 47, p. 27-58. Disponível em: http://www.scielo.br/ pdf/ln/n47/a03n47.pdf. Acesso em: 23.ago.2010.

2000. Rawls's Law of Peoples. Ethics, Washington, D.C., v. 110, n. 4, p. 669-696.

. 2001. Human Rights as a Common Concern. The American Political Science Review, Washington, DC, v. 95, n. 2, p. 269-282, June. Disponível em: http://academic2.american.edu/ $\sim \mathrm{d}$ f a $\mathrm{g}$ e $1 / \mathrm{b}$ e $\mathrm{i}$ t $\mathrm{z}$ humanrightsaspoliticalconcern.pdf. Acesso em: 23.ago. 2010 .

BRAGA, L. 2008. O debate cosmopolitismo $\mathrm{x}$ comunitarismo sobre os direitos humanos e a esquizofrenia das Relações Internacionais. Contexto Internacional, Rio de Janeiro, v. 30, n. 1, p. 141-169, jan.-abr. Disponível em: http:// www.scielo.br/pdf/cint/v30n1/04.pdf. Acesso em: 23.ago.2010.

BROWN, C. 1992. International Relations Theory: New Normative Approaches. New York: Columbia University.

COCHRAN, M. 1999. Normative Theory in International Relations: a Pragmatic Approach. Cambridge, UK: Cambridge University.

COHEN, G. A. 1992. Incentives, Inequality, and Community. In: PETERSON, G. B. (ed.). The Tanner Lectures on Human Values. V. 13. Salt Lake City: University of Utah. Disponível em: http://www.tannerlectures. utah.edu/lectures/ documents/cohen92.pdf. Acesso em: 23.ago.2010.

1997. Where the Action Is: On the Site of Distributive Justice. Philosophy and Public Affairs, Princeton, v. 26, n. 1, p. 3-30, Winter. Disponível em: http://philosophy.ucsd.edu/ faculty/rarneson/Courses/COHENG Awhereaction.pdf. Acesso em: 23.ago.2010.

GUIMARÃES, F. S. 2008. O debate entre comunitaristas e cosmopolitas e as teorias de Relações Internacionais: Rawls como uma via média. Contexto Internacional, Rio de Janeiro, v. 30, n. 3, p. 571-614, set.-dez. Disponível em: http://publique.rdc.puc-rio.br/ contextointernacional/media/v30n3a01.pdf. Acesso em: 23.ago.2010.
KEOHANE, R. O. 1984. After Hegemony: Cooperation and Discord in the World Political Economy. Princeton: Princeton University.

KEOHANE, R. O. \& NYE, J. S. 1989 [1977.] Power and Interdependence. 2. ed. Glenview: Pearson Scott Foresman.

KUPER, A. 2000. Rawlsian Global Justice: Beyond the Law of Peoples to a Cosmopolitan Law of Persons. Political Theory, Newbury Park, CA, v. 28, n. 5, p. 640-674, Oct.

LANDES, D. 1999. The Wealth and Poverty of Nations: Why Some Are so Rich and Some so Poor. New York: Norton.

MILNER, H. 2005. Globalization, Development, and International Institutions: Normative and Positive Perspectives. Perspectives on Politics, Cambridge (UK), v. 3, n. 4, p. 833-854, Dec. Disponível em: http://www9.georgetown.edu/ faculty/jrv24/milner_05.pdf. Acesso em: 23.ago. 2010 .

NOZICK, R. 1974. Anarchy, State, and Utopia. New York: Basic.

POGGE, T. W. 1989. Realizing Rawls. IthacaLondon: Cornell University.

1994a. Uma proposta de reforma: um dividendo global de recursos. Lua Nova, São Paulo, n. 34, p. 135-161. Disponível em: http:/ / b o o books?id=f44pmLV6sTMC\&lpg=PA135\&ots=so CUldEPGO\&dq $=U$ ma $\% 20$ proposta $\%$ $20 \mathrm{de} \% 20$ reforma\% 3 A \% 20 u m \% 20dividendo $\% 20$ global $\% 20$ de $\% 20$ recursos \&hl $=$ pt-BR \&pg $=$ PA $135 \# \mathrm{v}=$ onepage $\& \mathrm{q}=\mathrm{Uma} \% 2$ 0proposta\%20de\%20reforma:\%20um\%20 dividendo $\% 20$ global $\% 20 \mathrm{de} \% 20$ recursos $\& \mathrm{f}=$ false. Acesso em: 23.ago.2010.

. 1994b. An Egalitarian Law of People. Philosophy and Public Affairs, Princeton, v. 23, n. 3, p. 195-224, July. Disponível em: http:// www.jstor.org/pss/2265183. Acesso em: 23.ago. 2010 .

2001. Priorities of Global Justice. In: POGGE, T. W. (ed.). Global Justice. Oxford: Blackwell, p. 6-23.

RAWLS, J. 1971. A Theory of Justice. Cambridge, Mass.: Harvard University. 
. 1985. Justice as Fairness: Political not Metaphysical. Philosophy and Public Affairs, Princeton, v. 14, n. 3, p. 223-251, Summer. Disponível em: http://philosophyfaculty.ucsd.edu/faculty/rarneson/Philosophy\%20167/Rawlsjusticeasfairness.pdf. Acesso em: 23.ago.2010.

2000. [1993.] O liberalismo político. $2^{\mathrm{a}}$ ed. São Paulo: Ática.

2004. [1999.] O Direito dos Povos. São Paulo: M. Fontes.

SANDEL, M. J. 1982. Liberalism and the Limits of Justice. Cambridge, UK: Cambridge University.

1984. Morality and the Liberal Ideal. The New Republic, Washington, DC, 7.May, p. 1517. Também disponível em: SANDEL, M. J. 2005. Public Philosophy: Essays on Morality in Politics. Cambridge, Mass.: Harvard University, 2005, Part III.

VITA, A. 2003. Desigualdade e pobreza sobre uma perspectiva global. In: TOSTES, A. P. \& VITA, A. (orgs.). Justiça e processos democráticos transnacionais. São Paulo: Humanitas.
2006. O liberalismo igualitário em perspectiva doméstica e internacional. São Paulo. Tese (Livre-docência). Universidade de São Paulo.

WALTZ, K. N. 1970. The Myth of National Interdependence. In: KINDLEBERGER, C. P. (ed.). The International Corporation. Cambridge, Mass.: MIT, p. 205-223.

. 1983. Spheres of Justice. Oxford: Blackwell.

1990. The Communitarian Critique of Liberalism. Political Theory, v. 18, n. 1, p. 6-23, Feb. Disponível em: http://links.jstor.org/ sici?sici=0090-5917\%28199002\%2918\% 3A1\%3C6\%3ATCCOL\%3E2.0.CO\%3B2-5. Acesso em: 23.ago.2010.

WALZER, M. 1994. Thick and Thin: Moral Argument at Home and Abroad. Notre Dame: University of Notre Dame.

2006. Politics and Passion: Toward a More Egalitarian Liberalism. New Haven: Yale University.

WENAR, L. 2006. Why Rawls Is Not a Cosmopolitan Egalitarian. In: MARTIN, R. \& REIDY, D. (eds.). Rawls's Law of People: a Realistic Utopia? Oxford: Blackwell. 
RAWLS' DISCIPLES IN SEARCH OF A COSMOPOLITAN CONCEPTION OF INTERNATIONAL DISTRIBUTIVE JUSTICE

Gabriel Cepaluni and Feliciano de Sá Guimarães

In this article, we make the argument that some of John Rawl's "disciples", reflecting on the principles of international justice, have taken a position that is more consistent with the spirit of his $A$ Theory 
of Justice than the author himself has. Scholars such as Charles Beitz and Thomas Pogge defend mechanisms of international distributive justice that seem to be more in line with the cosmopolitanism of the "principle of difference" that can be found within A Theory of Justice than are other efforts that Rawls himself made in his later work, more oriented toward international issues, The Law of Peoples. More specifically, we maintain that Pogge and Beitz developed more solid arguments (the relativization of the principle of the absolute sovereignty of States and international transfer of natural resources) for transporting the "principle of difference" into the international arena than what can be found within Rawls' proposal on "the duty of aid" in The Law of Peoples. We thereby demonstrate that Rawls' disciples are more faithful to the cosmopolitan spirit at the international level than he himself was, for three reasons: their belief in a world community of fellow citizens within an international institutional structure; the idea that the global production of collective resources should be redistributed through a principle of dense distribution and, finally, the notion that redistribution that can only be just insofar as it demands the moral reform of international institutions (International Monetary Fund, World Trade Organization, World Bank, principle of sovereignty etc.) in such a way as to improve the life conditions of world's poorest peoples. Thus, this article discusses the most progressive legacy of authors whom, in taking their inspiration from Rawls, developed arguments that were more adequate than his own for nourishing a cosmopolitan spirit within the international arena.

KEYWORDS: normative theories of International Relations; distributive justice; reforming international institutions. 
LES DISCIPLES DE RAWLS A LA RECHERCHE D'UNE NOUVELLE CONCEPTION COSMOPOLITE DE JUSTICE DISTRIBUTIVE INTERNATIONALE

Gabriel Cepaluni et Feliciano de Sá Guimarães

Dans cet article, nous soutenons que quelques "disciples" de John Rawls, en pensant aux principes 
de justice internationale, présentent une position plus cohérente avec l'esprit de l'œuvre Une Théorie de la Justice, que son auteur lui-même. Des auteurs comme Charles Beitz et Thomas Pogge, défendent des mécanismes de justice distributive internationale plus cohérents avec le cosmopolitisme du "principe de la différence", de l'œuvre Une Théorie de la Justice que n'importe quel autre effort que Rawls fait dans ce sens, dans son œuvre postérieur, plus centré sur les questions internationales : Les Droits des Peuples. Plus spécifiquement, nous soutenons que Pogge et Beitz ont développé des arguments (la relativisation du principe de la souveraineté absolue des Etats et le transfert international de ressources naturelles), plus solides pour transporter le "principe de la différence" au scénario international, que la proposition "rawlsienne" de "devoir d'assistance", trouvée dans Le Droit des Peuples. Ainsi, nous démontrons que les disciples sont plus fidèles à l'esprit cosmopolite pour le plan international que Rawls, en raison de trois choses : la croyance de ces auteurs en une communauté globale de citoyens dans une structure institutionnelle internationale ; l'idée selon laquelle, la production globale de ressources collectives doit être redistribuée à partir d'un principe distributif dense ; et pour finir, une redistribution qui peut être juste seulement si elle exige des réformes morales des institutions internationales (Fonds Monétaire International, Organisation Mondiale du Commerce, Banque Mondiale, principe de la souveraineté etc.); dans le sens d'améliorer les conditions de vie des individus les plus pauvres de tous les peuples du système. Cet article a l'intention donc, de discuter l'héritage le plus progressif d'auteurs que, en s'inspirant en Rawls, ont développé des arguments plus cohérents avec l'esprit cosmopolite pour le plan international.

MOTS-CLES : théories normatives de Relations Internationales ; Justice Distributive ; réformes des institutions internationales. 